Journal of Engineering and Applied Sciences 14 (15): 4980-4988, 2019

ISSN: 1816-949X

(C) Medwell Journals, 2019

\title{
Selection Technique of Genetic Algorithm in Turing Machine
}

\author{
${ }^{1}$ Eman Ali Hussain and ${ }^{2}$ Yahya Mourad Abdul Abbass \\ ${ }^{1}$ Department of Mathematics, College of Science, Al-Mustansiriya University, Baghdad, Iraq \\ ${ }^{2}$ Ministry of Education, Educational Directorate Babylon, Baghdad, Iraq \\ emansultan@yahoo.com, yihiamor@yahoo.com
}

\begin{abstract}
Genetic algorithms are optimization methods using to solve a problem based on the model of natural evolution which has number of steps like initialization, selection, crossover and mutation. The selection is one important operator in these algorithms. Selection is the process of finding out the best individuals for mating process, so that, the offspring are produced child than the previous population in this study, we introduced a technique selection of Genetic algorithms in turing machine that advantages to introduce of the candidate solutions and the Genetic diversity. The proposed technique that does not dependence on Grammatical Evolution (GE) to find the candidate solutions also the speed of work and accuracy and storage capacity less.
\end{abstract}

Key words: Genetic algorithms, grammatical evolution, selection method, turing machine, differential equation, proposed

\section{INTRODUCTION}

Genetic algorithms was originally developed by Holland (1975). The theory of Genetic Algorithms (GAs) is a problem solving method that uses the concepts of Mendelian genetics and Darwinian evolution as the model of problem solving (Goldberg, 1989; Michalewicz., 2007). Holland's GA is a method for moving from one population of "chromosomes" to a new population by using the genetics operators like crossover, mutation and selection, chromosome contains a group of numbers that present as a candidate solution (Kumar et al., 2013). Selection is the stage of a Genetic algorithm in which from the search space selected a population of chromosomes, almost randomly, present as candidate solutions to optimize the problem (Michalewicz, 2007). The fitness function is used to evaluate the chromosomes in this population. By used selection operator to select chromosomes to be parents in the next generation, the next generation is finally formed by an alternative mechanism between parents and their off spring (DeJong, 2006). The selection operator is aimed to improve the best characteristics of good candidate solutions throughout generations which should converge to an acceptable solution of the optimization problem (Goldberg, 1989). Selection operator is the important parameter that may affect the performance of a GA (Back and Hoffmeister, 1991). The main objective of selection strategy is "the better is an individual the higher is its chance of being parent". The process that determines which solutions are to be preserved and allowed to reproduce and which ones deserve to die out (Mitchell, 1998). The main objective of the selection operator is to emphasize the good solutions and eliminate the bad solutions in a population while keeping the population size constant

Some types of selection techniques in GA: The types of selection techniques in GA consisting of six methods often used in Genetic algorithms, the most commonly used selection methods include roulette wheel selection, rank selection, tournament selection, Boltzmann selection. stochastic universal sampling and truncation selection. (Jebari and Madiafi, 2013). We will talk about roulette wheel selection briefly.

Roulette wheel selection: Roulette wheel also known as fitness proportionate selection is the simplest traditional GA selection techniques. In this technique placed all the chromosomes in the population on the roulette wheel according to their fitness value. Each individual is given a segment of roulette wheel whose size is proportional to the value of the fitness of the individual (Razali and Geraghty, 2011). If the fitness value is bigger impels the segment larger, then the virtual roulette wheel spinned. If the roulette wheel stops, the individual corresponding to the segment then are selected. Repeated the process until the wanted number of individuals is selected. The individuals have higher fitness have more probability of selection. There is no guarantee that good individuals will

Corresponding Author: Eman Ali Hussain, Department of Mathematics, College of Science, Al-Mustansiriya University, Baghdad, Iraq, emansultan@yahoo.com 


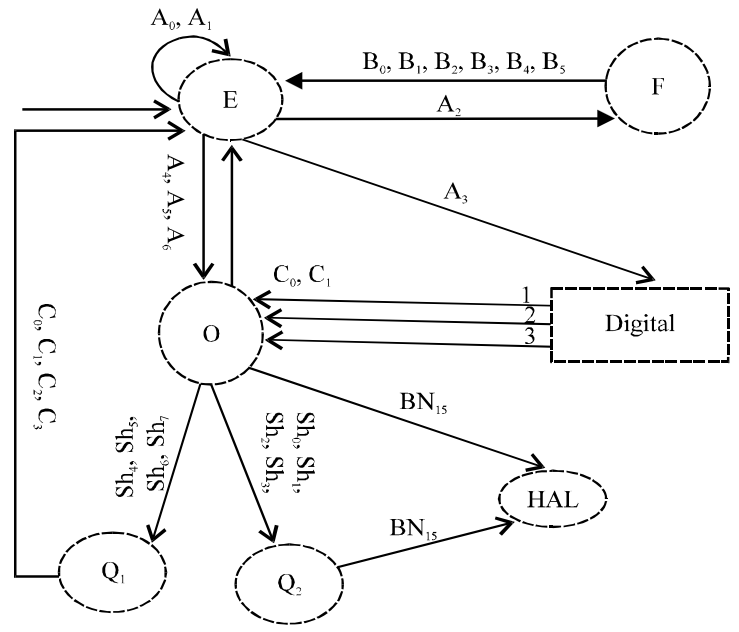

Fig. 1: Turning machine of grammatical evolution

find their way (Kumar and Jyotishree, 2012) into next generation. In roulette wheel, individuals are selected with a probability that is directly proportional to their fitness values. The probabilities of selecting a parent can be happen on.

Selection technique of GA in TM: The representation of the function $\mathrm{f}(\mathrm{x})$ in TM (Turing Machine) by using design of Grammatical Evolution (GE), the (Fig. 1 and 2) is design of TMGE (Turing Machine for Grammatical Evolution) with Table 1 for describe symbols, the sequence of symbols corresponding to the function $\mathrm{f}(\mathrm{x})$, the following definition of transformation from sequence of the production rules to the function $\mathrm{f}(\mathrm{x})$. This corresponding of the sequence $04001010044320315345003324 \mathrm{~F}$ and function:

$$
x+\sin (x+1)-\left(\frac{\left(x^{2}+1\right)}{x}\right)+3 x
$$

where, $\mathrm{N}_{\mathrm{t}-}=4, \mathrm{~N}_{\mathrm{prr}}=5$ and $\mathrm{N}_{\mathrm{op}}=8$, table of character using in graph of turing machine where $(\mathrm{E})$ is Expression, $(\mathrm{O})$ is Operation, $(\mathrm{F})$ is Function and (D) is Digital number.

Definition (4.1): TS is transformation from a space of sequence of production rules $\mathrm{p}=\left\{\mathrm{p}_{1}, \mathrm{p}_{2}, \ldots,\right\}$, applied in one of TM set into the set functions $F=\left\{\mathrm{f}_{1}, \mathrm{f}_{2}, \ldots,\right\}$ define by $\mathrm{TS}: \mathrm{P} \times \mathrm{TM} \rightarrow \mathrm{F}$

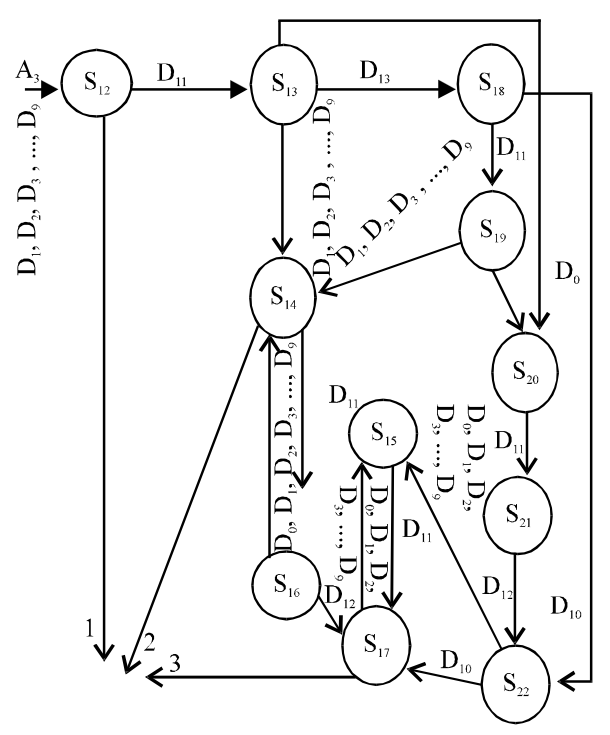

Fig. 2: Turning machine of digital number

Definition ( 4.2 ): If the function $f(x)$ in $R^{2}$, then denoted for:

- The Number of terms in $\mathrm{f}(\mathrm{x})$ by $\mathrm{N}_{\mathrm{t}}$

- The Number of pluses and minus by $\mathrm{N}_{\mathrm{PM}}$

- The number of operation in function by $\mathrm{N}_{\mathrm{op}}$

- The number of pluses, minus, multiplication, division and power in function by $\mathrm{N}_{0}-\mathrm{N}_{4}$ with respectively

$$
\begin{gathered}
\mathrm{N}_{\mathrm{pm}}=\mathrm{N}_{0}+\mathrm{N}_{1} \\
\mathrm{~N}_{\mathrm{op}}=\sum_{\mathrm{i}=0}^{4} \mathrm{~N}_{\mathrm{i}}
\end{gathered}
$$

$$
\Sigma=\{0,1,2,3,4,5,6,7,8,9,10,11,12,13,14,15\}
$$

Corresponding to the set of hexadecimal digits:

$$
\{0,1,2,3,4,5,6,7,8,9, A, B, C, D, E, F\}
$$

Example (4.1): From Fig. 1 and 2 and Table 1 the sequence $\mathrm{A}_{0}, \mathrm{~A}_{4}, \mathrm{C}_{4}, \mathrm{~A}_{0}, \mathrm{~A}_{3}, \mathrm{D}_{2}, \mathrm{C}_{0}, \mathrm{~A}_{2}, \mathrm{~B}_{0}, \mathrm{~A}_{4}, \mathrm{Sh}_{1}$ $\mathrm{BN}_{15}$, this corresponding of the sequence $04403202041 \mathrm{~F}$ and function $\mathrm{x}^{2}+\sin (\mathrm{x})$ then by the bellow follow table:

\begin{tabular}{|l|l|l|l|l|l|l|l|l|l|l|l|}
\hline $\mathrm{A}_{0}$ & $\mathrm{~A}_{4}$ & $\mathrm{C}_{4}$ & $\mathrm{~A}_{0}$ & $\mathrm{~A}_{3}$ & $\mathrm{D}_{2}$ & $\mathrm{C}_{0}$ & $\mathrm{~A}_{2}$ & $\mathrm{~B}_{0}$ & $\mathrm{~A}_{4}$ & $\mathrm{Sh}_{1}$ & $\mathrm{BN}_{15}$ \\
\hline 0 & 4 & 4 & 0 & 3 & 2 & 0 & 2 & 0 & 4 & 1 & 15 \\
\hline 0 & 4 & 4 & 0 & 3 & 2 & 0 & 2 & 0 & 4 & 1 & $\mathrm{~F}$ \\
\hline
\end{tabular}




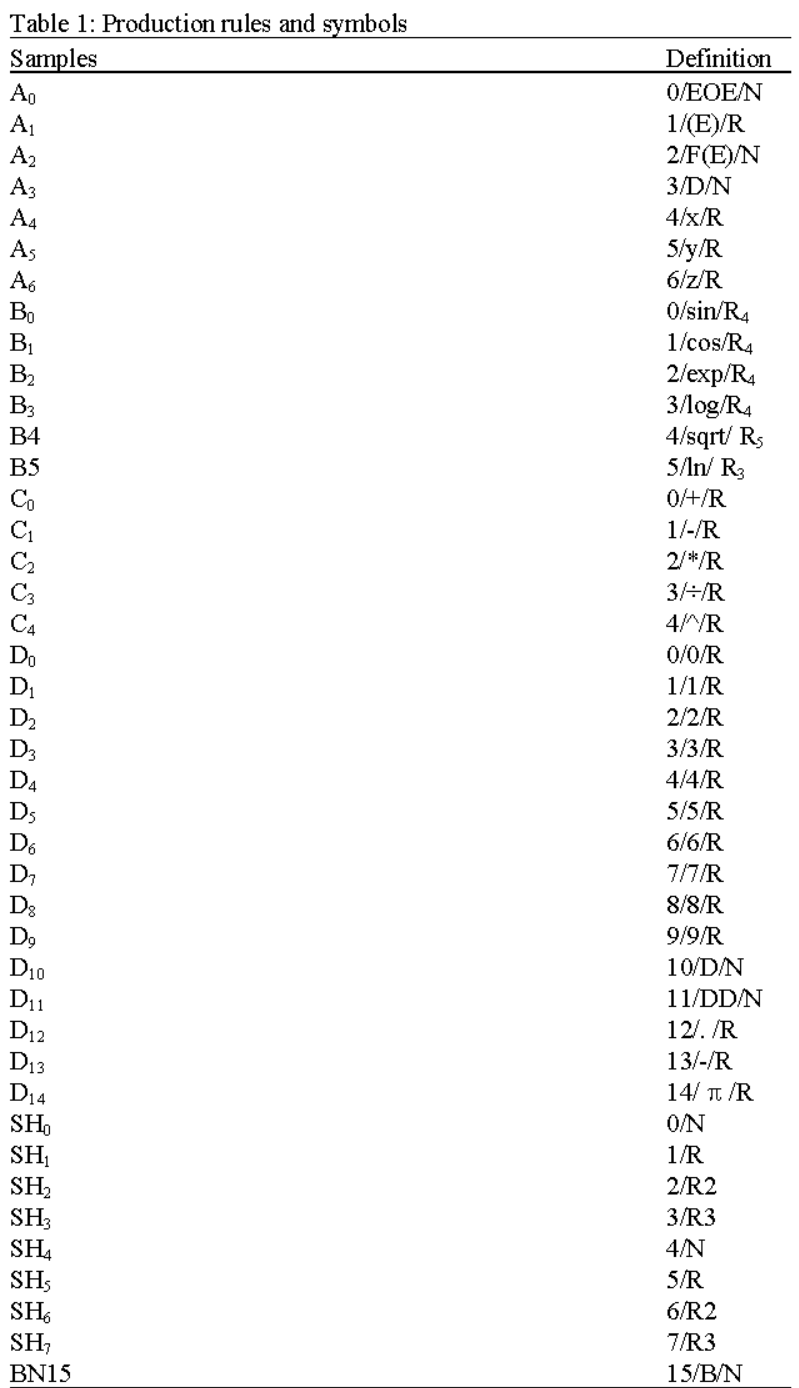

Where:

$$
\mathrm{N}_{\mathrm{t}}=2, \mathrm{~N}_{\mathrm{pm}}=1 \text { and } \mathrm{N}_{\mathrm{op}}=2
$$

Example (4.2): From Fig. 1 and 2 Table 1, the sequence $A_{2}$ $\mathrm{B}_{0}, \mathrm{~A}_{0}, \mathrm{~A}_{4}, \mathrm{C}_{0}, \mathrm{~A}_{3}, \mathrm{D}_{3}, \mathrm{BN}_{15}$, this corresponding of the sequence $2004033 \mathrm{~F}$ and function $\sin (\mathrm{x}+3)$ then by Table 2:
Table 2: Calculation the number of terms

\begin{tabular}{llccc}
$\begin{array}{l}\text { Symbols of } \\
\text { expression }\end{array}$ & Expression & $\begin{array}{c}\text { Unknown } \\
\text { operation }\left(\mathrm{U}_{\mathrm{N}}\right)\end{array}$ & $\begin{array}{c}\text { No. of } \\
\text { terms }\left(\mathrm{N}_{\mathrm{H}}\right)\end{array}$ & $\begin{array}{c}\text { Trace of } \\
\text { operation }\left(\mathrm{T}_{\text {oq }}\right)\end{array}$ \\
\hline $\mathrm{A}_{0}$ & $\mathrm{EOE}$ & 1 & 1 & 0 \\
$\mathrm{~A}_{3}, \mathrm{D}_{2}$ & $2 \mathrm{OE}$ & 1 & 1 & 0 \\
$\mathrm{C}_{2}$ & $2 * \mathrm{E}$ & 0 & 1 & 0 \\
$\mathrm{~A}_{0}, \mathrm{~A}_{4}$ & $\mathrm{xOE}$ & 1 & 1 & 0 \\
$\mathrm{C}_{4}$ & $\mathrm{X}^{\mathrm{E}}$ & 0 & 1 & 0 \\
$\mathrm{~A}_{0}, \mathrm{~A}_{3}, \mathrm{D}_{2}$ & $\mathrm{X}^{2 \mathrm{OE}}$ & 1 & 1 & 0 \\
$\mathrm{C}_{1}$ & $\mathrm{X}^{2}-\mathrm{E}$ & 0 & 2 & 0 \\
$\mathrm{~A}_{0}, \mathrm{~A}_{3}, \mathrm{D}_{3}$ & $3 \mathrm{OE}$ & 1 & 2 & 0 \\
$\mathrm{C}_{2}$ & $3 * \mathrm{E}$ & 0 & 2 & 0 \\
$\mathrm{~A}_{0}, \mathrm{~A}_{2}, \mathrm{~B}_{0}$ & $\operatorname{Sin}(\mathrm{E}) \mathrm{OE}$ & 1 & 2 & 1 \\
$\mathrm{~A}_{0}, \mathrm{~A}_{4}$ & $\mathrm{Sin}(\mathrm{xOE}) \mathrm{OE}$ & 2 & 2 & 1 \\
$\mathrm{C}_{0}$ & $\mathrm{Sin}(\mathrm{x}+\mathrm{E}) \mathrm{OE}$ & 1 & 2 & 1 \\
$\mathrm{~A}_{0}, \mathrm{~A}_{3}, \mathrm{D}_{3}$ & $\mathrm{Sin}(\mathrm{x}+3 \mathrm{OE}) \mathrm{OE}$ & 2 & 2 & 1 \\
$\mathrm{C}_{2}$ & $\mathrm{Sin}(\mathrm{x}+3 * \mathrm{E}) \mathrm{OE}$ & 1 & 2 & 1 \\
$\mathrm{~A}_{5}, \mathrm{Sh}_{1}$ & $\mathrm{Sin}(\mathrm{x}+3 \mathrm{y}) \mathrm{OE}$ & 1 & 2 & 0 \\
$\mathrm{C}_{0}$ & $\mathrm{Sin}(\mathrm{x}+3 \mathrm{y})+\mathrm{E}$ & 0 & 3 & 0 \\
$\mathrm{~A}_{0}$ & $+\mathrm{EOE}$ & 1 & 3 & 0 \\
$\mathrm{~A}_{3}, \mathrm{D}_{2}$ & $2 \mathrm{OE}$ & 1 & 3 & 0 \\
$\mathrm{C}_{2}$ & $2 * \mathrm{E}$ & 0 & 3 & 0 \\
$\mathrm{~A}_{4}$ & $2 * \mathrm{E}$ & 0 & 3 & 0 \\
$\mathrm{BN}_{15}$ & $2 * x$ & 0 & 3 & 0 \\
\hline
\end{tabular}

\begin{tabular}{|l|l|l|l|l|l|l|l|}
\hline $\mathrm{A}_{2}$ & $\mathrm{~B}_{0}$ & $\mathrm{~A}_{0}$ & $\mathrm{~A}_{4}$ & $\mathrm{C}_{0}$ & $\mathrm{~A}_{3}$ & $\mathrm{D}_{3}$ & $\mathrm{BN}_{15}$ \\
\hline 2 & 0 & 0 & 4 & 0 & 3 & 3 & 15 \\
\hline 2 & 0 & 0 & 4 & 0 & 3 & 3 & $\mathrm{~F}$ \\
\hline
\end{tabular}

Where:

$$
\mathrm{N}_{\mathrm{t}}=\mathrm{N}_{\mathrm{pm}}=\mathrm{N}_{\mathrm{op}}=1
$$

Example (4.3): From Fig. 1 and 2, Table 1, the sequence $\mathrm{A}_{0} \quad \mathrm{~A}_{1}, \mathrm{~A}_{0}, \mathrm{~A}_{4}, \mathrm{C}_{0}, \mathrm{~A}_{5}, \mathrm{Sh}_{5}, \mathrm{C}_{4}, \mathrm{~A}_{3}, \mathrm{D}_{3}, \mathrm{NB}_{15}$, this corresponding of the sequence $0104055433 \mathrm{~F}$ and function $(\mathrm{x}+\mathrm{y})^{3}$ then by the Table 2 : Where:

$$
\mathrm{N}_{\mathrm{t}}=\mathrm{N}_{\mathrm{pm}}=\mathrm{N}_{\mathrm{op}}=1
$$

Example (4.4): From Fig. 1 and 2 Table 1, the sequence:

$$
\begin{aligned}
& A_{0}, A_{0}, A_{3}, D_{11}, D_{2}, D_{5}, D_{10}, D_{12}, D_{1}, \\
& D_{10}, D_{1}, C_{2}, A_{4}, C_{4}, A_{0}, A_{3}, D_{3}, \\
& C_{1}, A_{0}, A_{3}, D_{3}, C_{2}, A_{0}, A_{4}, C_{4}, A_{0}, A_{3}, D_{2}, \\
& C_{0}, A_{0}, A_{3}, D_{2}, C_{2}, A_{0}, A_{4}, \\
& C_{0}, A_{3}, D_{11}, D_{1}, D_{1}, B_{15}
\end{aligned}
$$

\begin{tabular}{|l|l|l|l|l|l|l|l|l|l|l|}
\hline $\mathrm{A}_{0}$ & $\mathrm{~A}_{1}$ & $\mathrm{~A}_{0}$ & $\mathrm{~A}_{3}$ & $\mathrm{C}_{0}$ & $\mathrm{~A}_{5}$ & $\mathrm{Sh}_{5}$ & $\mathrm{C}_{4}$ & $\mathrm{~A}_{3}$ & $\mathrm{D}_{3}$ & $\mathrm{BN}_{15}$ \\
\hline 0 & 1 & 0 & 4 & 0 & 5 & 5 & 4 & 3 & 3 & 15 \\
\hline 0 & 1 & 0 & 4 & 0 & 5 & 5 & 4 & 3 & 3 & $\mathrm{~F}$ \\
\hline
\end{tabular}

This corresponding of the sequence. 003B25AC1A124403310332044032003220403B11F
And function:

$$
25.11 x^{3}-3 x^{2}+2 x+11
$$




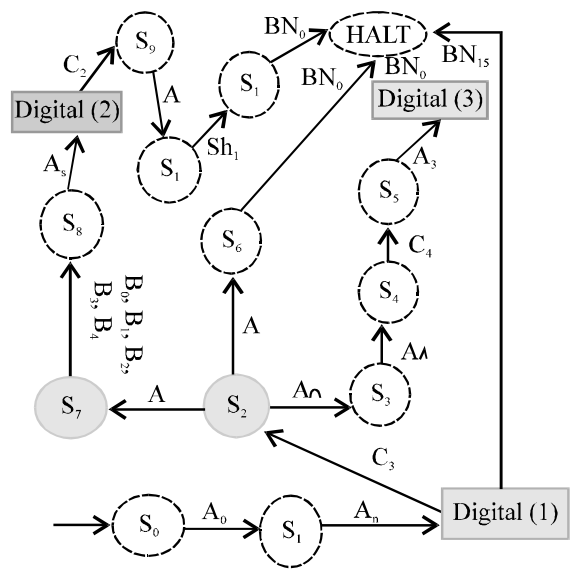

Fig. 3: Standard simple terms

Where:

$$
\mathrm{N}_{\mathrm{t} .}=4, \mathrm{~N}_{\mathrm{pm} .}=3 \text { and } \mathrm{N}_{\mathrm{op} .}=8
$$

Example (4.5): From Fig. 2, 3 and Table 1, the sequence $\mathrm{A}_{0}, \mathrm{~A}_{0}, \mathrm{~A}_{3}, \mathrm{D}_{6}, \mathrm{C}_{2}, \mathrm{~A}_{4}, \mathrm{C}_{0}, \mathrm{~A}_{0}, \mathrm{~A}_{1}, \mathrm{~A}_{0}, \mathrm{~A}_{4}, \mathrm{C}_{0}, \mathrm{~A}_{3}, \mathrm{D}_{1}, \mathrm{Sh}_{1}, \mathrm{C}_{4}$, $\mathrm{A}_{3}, \mathrm{D}_{2}, \mathrm{BN}_{15}$, this corresponding of the sequence $003624001040311432 \mathrm{~F}$ and function $6 \mathrm{x}+(\mathrm{x}+1)^{2}$.

Where:

$$
\mathrm{N}_{\mathrm{t} .}=2, \mathrm{~N}_{\mathrm{pm} .}=2 \text { and } \mathrm{N}_{\mathrm{op} .}=4
$$

Example (4.6): From Fig. 1 and 2, Table 1, the sequence:

$$
\begin{aligned}
& A_{0}, A_{4}, \\
& C_{0}, A_{0}, A_{2}, B_{0}, A_{0}, A_{4}, C_{0}, A_{3}, D_{1}, S_{1}, \\
& C_{1}, A_{0}, A_{1}, A_{0}, A_{1}, A_{0}, A_{0}, A_{4}, C_{4}, A_{3}, \\
& D_{2}, C_{0}, A_{3}, D_{1}, S h_{5}, C_{3}, A_{4}, S h_{5}, \\
& C_{0}, A_{0}, A_{3}, D_{3}, C_{2}, A_{4}, B N_{15}
\end{aligned}
$$

\section{Congruent sequences production rules}

Definition (4.3): The sequence $\mathrm{S}_{\mathrm{Q} 1}$ is a congruent to the sequence $\mathrm{S}_{\mathrm{Q}_{2}}$, if and only if the functions corresponding to the sequences $\mathrm{S}_{\mathrm{Q}_{1}}$ and $\mathrm{S}_{\mathrm{Q}_{2}}$ are equal. Denoted by $\mathrm{S}_{\mathrm{Q}_{1}} \cong$ $\mathrm{S}_{\mathrm{Q} 2}$

Example (4.7): Let $f(x)=x^{2}+5$ and $g(x)=1 * x^{2}-0+5$, the sequence $S_{Q 1}$ of $f(x)$ is $A_{0}, A_{4}, C_{4}, A_{0}, A_{3}, D_{2}, C_{0}, A_{3} D_{5}$, $\mathrm{BN}_{15}$. And the sequence $\mathrm{S}_{\mathrm{O} 2}$ of $\mathrm{g}(\mathrm{x})$ is $\mathrm{A}_{0}, \mathrm{~A}_{3} \mathrm{D}_{1}, \mathrm{C}_{2}, \mathrm{~A}_{0}$, $\mathrm{A}_{4}, \mathrm{C}_{4}, \mathrm{~A}_{0}, \mathrm{~A}_{3}, \mathrm{D}_{2}, \mathrm{C}_{1}, \mathrm{~A}_{0}, \mathrm{~A}_{3}, \mathrm{D}_{0}, \mathrm{C}_{0}, \mathrm{~A}_{3}, \mathrm{~A}_{5} \mathrm{BN}_{15}$. Since, $\mathrm{f}(\mathrm{x})=\mathrm{g}(\mathrm{x})$, then $\mathrm{S}_{\mathrm{Q}_{1}} \cong \mathrm{S}_{\mathrm{Q}_{2}}$. In above example where remove $\mathrm{A}_{3}, \mathrm{D}_{1}, \mathrm{C}_{2}, \mathrm{~A}_{0}$, and $\mathrm{C}_{1}, \mathrm{~A}_{0}, \mathrm{~A}_{3}, \mathrm{D}_{0}$, from $\mathrm{S}_{\mathrm{Q} 2}$, then $\mathrm{S}_{\mathrm{Q} 1}=\mathrm{S}_{\mathrm{Q} 2}$.

Definition (4.4): If $\mathrm{S}_{\mathrm{Q} 1}$ and $\mathrm{S}_{\mathrm{Q} 2}$ are sequences of production rules, then the definition of the function $\eta\left(\mathrm{S}_{\mathrm{Q} 1}\right)$ is a sequence of production rules such that $\eta\left(\mathrm{S}_{\mathrm{Q} 1}\right)=\mathrm{S}_{\mathrm{Q} 2}$
Note: The function $\eta$ to remove identity from sequence for each operations:

- Addition and subtraction: $\mathrm{a}=\mathrm{a} \pm 0=0 \pm \mathrm{a}$

- Multiplication and division: $\mathrm{a}=1^{*} \mathrm{a}=\mathrm{a}^{*} 1, \mathrm{a}=\mathrm{a} / 1$

- Power: $\mathrm{a}=\mathrm{a}^{1}$

Note: Equivalent functions, for example, $\mathrm{x}+\mathrm{x}=2 \mathrm{x}, \sin$ $(\phi+\pi)=-\sin (\phi), \ldots$

\section{MATERIALS AND METHODS}

The number of terms in function: The aim of this study to calculate the number of terms in sequence of production rules corresponding to function. In mathematics algebra the term is either a single number (belong to real number) or variable $(x, y, \ldots$,$) or numbers$ and variables multiplied together $(3 \mathrm{x}, 5.1 \mathrm{y}, \ldots$,$) . The terms$ are separated by plus operation (+sign) or minus operation (-sign). To calculate the number of terms by summation the number plus and minus out of brackets (Table 3 and 4). The algorithm to find the number of terms in sequence of production rules where the following calculation:

$$
\begin{aligned}
& A_{0}, A_{3}, D_{2}, C_{2}, A_{0}, A_{4}, C_{4}, A_{0}, \\
& A_{3}, D_{2}, C_{1}, A_{0}, A_{3}, D_{3}, C_{2}, A_{0}, A_{2}, \\
& B_{0}, A_{0}, A_{4}, C_{0}, A_{0}, A_{3}, D_{3}, C_{2}, A_{5}, \\
& S_{1}, C_{0}, A_{0}, A_{2}, D_{2}, C_{2}, A_{4}, B N_{15}
\end{aligned}
$$

Table 2 calculation the number of terms. The number of terms is $\left(\mathrm{N}_{\mathrm{t}}\right) 3$ and the function is $2 \mathrm{x}^{2}-3 \sin (\mathrm{x}+3 \mathrm{y})+2 \mathrm{x}$ where.

Trace of operation: To check cursor of calculation inside bracket or outside and denoted by $\mathrm{T}_{\mathrm{Op}}$.

Unknown operation: Just only operand but unknown the operation and denoted by $U_{\mathrm{N}}$. The number of terms, initial first value is one. Now by using the following, example for calculate number of terms in the following sequence (algortihm 1):

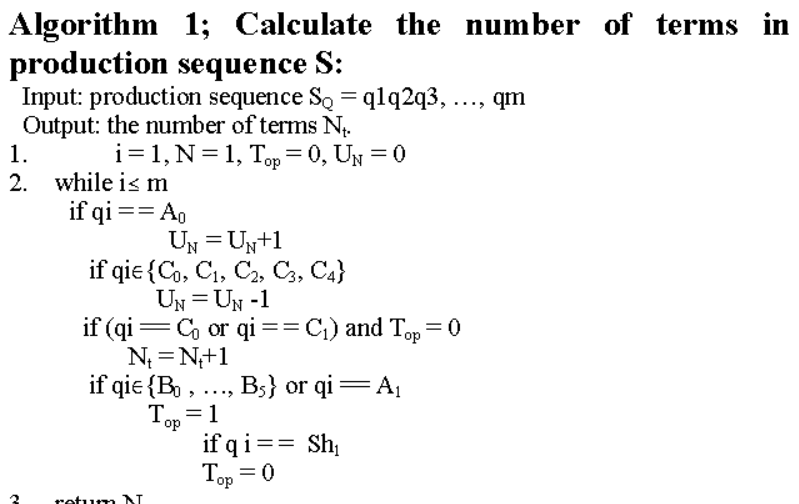




\begin{tabular}{|c|c|c|c|c|}
\hline Sample & Definition & No. & Sample & Definition \\
\hline $\mathrm{A}_{0}$ & $0 / \mathrm{EOE} / \mathrm{N}$ & 16 & $\mathrm{D}_{2}$ & $2 / 2 / \mathrm{R}$ \\
\hline $\mathrm{A}_{2}$ & $2 / \mathrm{F}(\mathrm{E}) / \mathrm{N}$ & 17 & $\mathrm{D}_{3}$ & $3 / 3 / \mathrm{R}$ \\
\hline $\mathrm{A}_{3}$ & $3 / \mathrm{D} / \mathrm{N}$ & 18 & $\mathrm{D}_{4}$ & $4 / 4 / R$ \\
\hline $\mathrm{A}_{4}$ & $4 / \mathrm{x} / \mathrm{R}$ & 19 & $\mathrm{D}_{5}$ & $5 / 5 / \mathrm{R}$ \\
\hline $\mathrm{B}_{0}$ & $0 / \sin / R_{4}$ & 20 & $\mathrm{D}_{6}$ & $6 / 6 / \mathrm{R}$ \\
\hline $\mathrm{B}_{1}$ & $1 / \cos / \mathrm{R}_{4}$ & 21 & $\mathrm{D}_{7}$ & $7 / 7 / \mathrm{R}$ \\
\hline $\mathrm{B}_{2}$ & $2 / \exp / \mathrm{R}_{4}$ & 22 & $\mathrm{D}_{8}$ & $8 / 8 / \mathrm{R}$ \\
\hline $\mathrm{B}_{3}$ & $3 / \log / \mathrm{R}_{4}$ & 23 & $\mathrm{D}_{9}$ & $9 / 9 / \mathrm{R}$ \\
\hline B4 & 4/sqrt/ $\mathrm{R}_{5}$ & 24 & $\mathrm{D}_{10}$ & $10 / \mathrm{D} / \mathrm{N}$ \\
\hline B5 & $5 / \ln / \mathrm{R}_{3}$ & 25 & $\mathrm{D}_{11}$ & $11 / \mathrm{DD} / \mathrm{N}$ \\
\hline $\mathrm{C}_{0}$ & $0 /+/ \mathrm{R}$ & 26 & $\mathrm{D}_{12}$ & 12/. /R \\
\hline $\mathrm{C}_{1}$ & $1 /-/ R$ & 27 & $\mathrm{D}_{13}$ & $13 /-/ \mathrm{R}$ \\
\hline $\mathrm{C}_{2}$ & $2^{*} / \mathrm{R}$ & 28 & $\mathrm{D}_{14}$ & $14 / \partial / R$ \\
\hline $\mathrm{C}_{4}$ & $4 / \wedge / \mathrm{R}$ & 29 & $\mathrm{SH}_{1}$ & $1 / \mathrm{R}$ \\
\hline $\mathrm{D}_{0}$ & $0 / 0 / \mathrm{R}$ & 30 & BN15 & $15 / \mathrm{B} / \mathrm{N}$ \\
\hline$\underline{D_{1}}$ & $1 / 1 / \mathrm{R}$ & & & \\
\hline
\end{tabular}

Table 4: Number of terms in production

\begin{tabular}{lllll}
\hline Type & $\mathrm{T} 1$ & $\mathrm{~T} 2$ & $\ldots$ & $\mathrm{T}_{\mathrm{rf}}$ \\
\hline Frequency appear & $\mathrm{n}_{1}$ & $\mathrm{n}_{2}$ & $\ldots$ & $\mathrm{n}_{\text {tf }}$
\end{tabular}

\section{Standard simple terms}

The simple term is one of the following types: Standard Function (SF): A $\mathrm{f}(\mathrm{bx})$ where $\mathrm{f}(\mathrm{x}) \in\left\{\sin (\mathrm{x}), \cos (\mathrm{x}), \mathrm{e}^{\mathrm{x}}, \log (\mathrm{x})\right.$, $\operatorname{sqrt}(\mathrm{x}), \ln (\mathrm{x})\}$ and $\mathrm{a}, \mathrm{b}^{\mathrm{a}} \mathrm{R}$ such as $2.1 \sin (4 \mathrm{x})$ or -4.1 $\mathrm{e}^{(5 \mathrm{x})}$.

Constant Function (CF): The $\mathrm{C}$ where, $\mathrm{c}$ is a constant $\mathrm{c} \in \mathrm{R}$, such as 45.67676 or -4532.87 .

Power Function (PF): $A x^{n}$ where $a \in \mathbb{R}$ and $n \in \mathbb{R}$ such as.

Line Function (LF): $\mathrm{A} \mathrm{x}^{\mathrm{n}}$ where, $\mathrm{a} \in \mathbb{R}$ such as $6.1 \mathrm{x}, \mathrm{x},-3 \mathrm{x}$ Fig. 2 and 3 to create random function of above types $\mathrm{SF}, \mathrm{CF}, \mathrm{PF}$ and LF from two Fig. 2 and 3 of TM, the size of the set of States $\mathrm{S}$ is 17 states.

Where:

$$
\mathrm{S}=\left\{\mathrm{S}_{0}, \mathrm{~S}_{1} \& \mathrm{~S}_{11}, \mathrm{~S}_{12}, \mathrm{~S}_{13} \& \mathrm{~S}_{16}, \mathrm{HALT}\right\},|\mathrm{S}|=17
$$

And the number of elements in $\Gamma$ is 27 :

$$
\begin{aligned}
& \Gamma=\left\{A_{0}, A_{2}, A_{4}, B_{0}, \& B_{5}, D_{0}, D_{1}, \ldots,\right. \\
& \left.D_{9}, D_{11}, D_{12}, D_{14}, S_{1}, B_{0}\right\}|S|=27
\end{aligned}
$$

Selection random simple term: To select a random term from Fig. 3 and 2 by generate random digit in States S2, S7 and block of states of digits denoted by digital (1-3).

In block of digital (1) in Fig. 3, there are two paths, one for constant function ( forward $\mathrm{BN}_{15}$ ) and other $\mathrm{C}_{2}$ (have three paths in State S2), then there two paths $k=15$ for $\mathrm{BN}_{15}$ and $\mathrm{k}=2$ for $\mathrm{C}_{2}$, if $\mathrm{r}$ random between 0 and 1 , then generate random $\mathrm{k}$ where (Eq. 1):

$$
\mathrm{k}=28-13\lceil\mathrm{r}+0.75\rceil, 0<\mathrm{r}<1
$$

In state $\mathrm{S} 2$ of Fig. 3, the random number 0,2 and 4 if $\mathrm{r}$ random between 0 and 1 , then generate random $A_{k}$ where (Eq. 2):

$$
\mathrm{k}=2\lceil 3 \mathrm{r}\rceil-2,0<\mathrm{r}<1
$$

In state $\mathrm{S} 7$ of Fig. 3 , the random is $0,1,2,3,4$ and 5 , if $\mathrm{r}$ random between 0 and 1 , then generate random $B_{k}$ where (Eq. 3):

$$
\mathrm{k}=\lfloor 6 \mathrm{r}\rfloor, 0<\mathrm{r}<1
$$

$$
\begin{array}{ll}
\min \beta, & \beta \geq 0 \\
\text { Such that } & 10^{\beta} \mathrm{D}_{\mathrm{p}}-\left\lfloor 10^{\beta} \mathrm{D}_{\mathrm{p}}\right\rfloor=0
\end{array}
$$

How partition a random digit: To partition a random digit $\mathrm{x}$ in digital block of Fig. 3 where $\mathrm{x}$ is depended on the size of number if $\mathrm{x}$ digit belong the interval $[\mathrm{a}, \mathrm{b}]$ where $\mathrm{x}$ have integer part $\mathrm{I}_{\mathrm{p}}(\mathrm{x})$ and decimal part $\mathrm{D}_{\mathrm{p}}(\mathrm{x})$,

Integer part: To calculate the sequence of $\alpha$ decimal places of integer part of $x$ is $I_{p}$ where:

$$
I_{p}(x)=\lfloor x\rfloor \mid
$$

Example(4.8): If $x=528.25$, then $I_{p}(x)=\||528.25|$

$=528$. The number of digit in $I_{p}$ is $\alpha$ where, (Eq. 4):

$$
\alpha=\left\{\begin{array}{cc}
{\left[\log _{10}\left(I_{p}\right)\right] x \neq 0} \\
1 & x=0
\end{array}\right.
$$

From above example $\alpha=\left\lceil\log _{10}(528)\right\rceil=3$. The decimal places of $I_{p}$ from left to right are :

Where:

$$
I_{p}=\sum_{k=1}^{\infty} I_{k} 10^{k-1}
$$

$$
\begin{gathered}
I_{k}=\left\lfloor 10^{1-k} x_{a-k+1}\right\rfloor, k=\alpha, \alpha,-1, \ldots, 2,1 \\
x_{k+1}=x_{k}-10^{\alpha \cdot k} I_{\alpha \cdot k+1} x_{1}=I_{p}
\end{gathered}
$$

From above example:

$$
\begin{aligned}
& \mathrm{x}_{1}=528, \mathrm{I}_{3}=\left\lfloor 10^{1-3} \mathrm{x}_{3}\right\rfloor=5 \\
& \mathrm{x}_{2}=\mathrm{x}_{1}-10^{2} \mathrm{I}_{3}=28, \mathrm{I}_{2}=\left\lfloor 10^{1-2} \mathrm{x}_{2}\right\rfloor=2 \\
& \mathrm{x}_{3}=\mathrm{x}_{2}-10^{1} \mathrm{I}_{2}=8, \mathrm{I}_{1}=\left\lfloor 10^{1-1} \mathrm{x}_{1}\right\rfloor=8
\end{aligned}
$$

Example (4.9): If $x=-368<0$, then $I_{p}=368$ and $\alpha=$ $\left[\log \_10(368)\right]=3$, then $I_{1}=8 \cdot I_{2}=6 \cdot I_{3}=3$.

Decimal part: The decimal part of the number $\mathrm{x}$ is:

$$
D_{p}(x)=|x-\lfloor x\rfloor|
$$


From above example, since, $x=528.25$, then $D_{p}(x)=$ $1528.25-\left\lfloor 528.25 \|=0.25\right.$. The number of digit in decimal $\mathrm{D}_{\mathrm{p}}$ is $\beta \geq 0$ where $\beta$ is minimum value of. From above example $D_{\mathrm{p}}=0.25$, then $10^{2} 0.25-\left\lfloor 10^{2} \times 0.25\right\rfloor=0 \beta=2$. Also, for example, $\mathrm{x}=12.0254$, then $\mathrm{I}_{\mathrm{p}}=12, \mathrm{D}_{\mathrm{p}}=0.0254, \alpha=2$ and $\beta=4$. The places decimal parts of $D_{p}$ from left to right are:

$$
\begin{aligned}
& D_{p}=\sum_{k=1}^{\beta} d \times 10^{-k} \\
& d_{k}=\left\lfloor 10 x_{k}\right\rfloor, k=1,2, \ldots, \beta \\
& x_{k}=10 x_{k-1}-d_{k-1}
\end{aligned}
$$

Where:

$$
\mathrm{x}_{1}=\mathrm{D}_{\mathrm{p}}
$$

From above example:

$$
\begin{aligned}
& \mathrm{x}_{1}=0.25, \mathrm{~d}_{1}=\left\lfloor 10 \mathrm{x}_{2}\right\rfloor=2 \\
& \mathrm{x}_{2}=\mathrm{x}_{1}-10^{-1} \mathrm{~d}_{1}=0.05, \mathrm{~d}_{2}=\left\lfloor 10^{2} \mathrm{x}_{1}\right\rfloor=5
\end{aligned}
$$

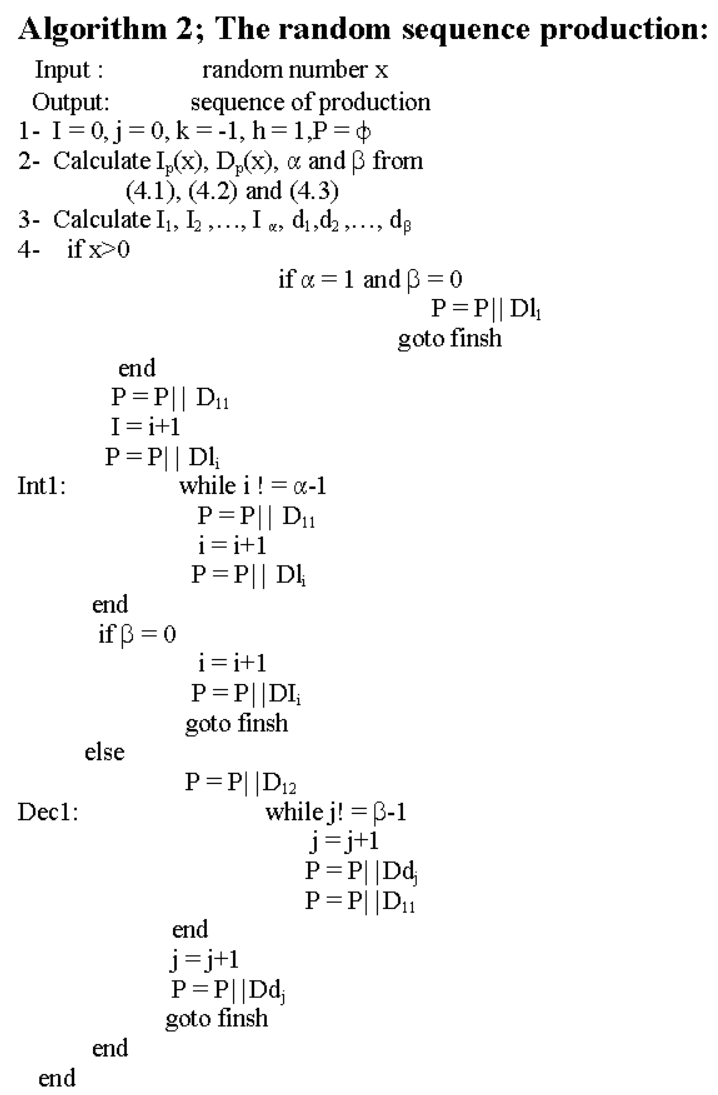

\section{RESULTS AND DISCUSSION}

Generate sequence of $I_{0}, I_{1}, I_{2}, \ldots, I_{\alpha}$ and $d_{1}, d_{2}, \ldots, d_{\beta}$ : From Fig. 2 for every number $x \in \mathbb{R}$, there are sequence $I_{0}$, $I_{1}, I_{2}, \ldots, I_{\infty} d_{b} d_{2}, \ldots, d_{\beta}$ corresponding to production sequence $D_{\mathrm{il}}, D_{\mathrm{i} 2}, \ldots, \mathrm{D}_{\mathrm{iq}}$ for example 83.52 where $\mathrm{I}_{1}=3, \mathrm{I}_{2}$ $=8, \mathrm{~d}_{1}=5$ and $\mathrm{d}_{2}=2$, corresponding $\mathrm{D}_{11}, \mathrm{D}_{8}, \mathrm{D}_{11}, \mathrm{D}_{3}, \mathrm{D}_{11}$, $\mathrm{D}_{12}, \mathrm{D}_{5}, \mathrm{D}_{11}, \mathrm{D}_{2}$ or B8B3BC5B2, the following algorithm to find the sequence random number.

The chromosome for t-terms: The chromosome is a sequence formed from the numbers $\{0,1,2,3,4,5,6,7,8$, $9,10,11,12,13,14,15\}$ corresponding $\{0,1,2,3,4,5,6,7$, $8,9, \mathrm{~A}, \mathrm{~B}, \mathrm{C}, \mathrm{D}, \mathrm{E}, \mathrm{F}\}$. For example, by used Fig. 3 and 2 and Table 2, then the sequence of $03 \mathrm{~B} 32 \mathrm{AC} 1204432 \mathrm{~F}$ is a corresponding to one term $2.1 \mathrm{x}^{2}$, of one term. The chromosome of t-terms $(t=3)$ separated by character $F$, for example, $\sin (x)+x^{2}+2.1 x^{3}$ is 03322031241F031204432F03B2BC2204433F.

Selection algorithm for TM: If is a fitness chromosomes (t-terms) function of Table 5 :

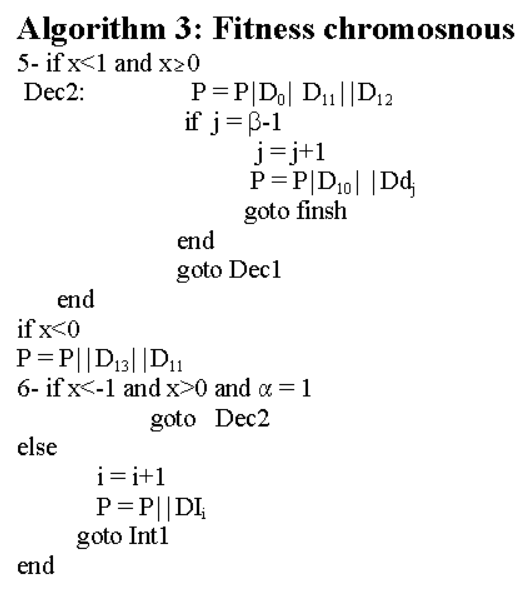

Finish DE's (Differential Equations):

$$
g(x, y(x)), \frac{d y}{d x}, \frac{d^{2} y}{d^{n} x}, \ldots, \frac{d^{n} y}{d^{n} x}=0
$$

Have higher probability to be selected for the next generation in TM where $n \epsilon z^{+}$is order of DE's. To compute the fitness of each chromosome is by calculate fitness probability, $\mathrm{fp}(\mathrm{x})$, then we add one to the fitness probability $\mathrm{fp}(\mathrm{x})$ for avoid divide by zero where (Eq. 4):

$$
f(x)=\frac{1}{f p(x)+1}
$$

And where fitness probability is (Eq. 5):

$$
\begin{aligned}
& f\left(x_{i}\right)=D\left(x_{i}, y\right)\left(x_{i}\right), \frac{d y}{d x} \\
& \left|x=x_{i}, \frac{d^{2} y}{d^{2} x}\right|_{x=x_{i}}, \ldots,\left.\frac{d^{n} y}{d^{n} x}\right|_{x}=x_{i}
\end{aligned}
$$




\begin{tabular}{|l|l|l|l|l|l|l|l|l|l|l|l|l|l|}
\hline $\mathrm{A}_{0}$ & $\mathrm{D}_{11}$ & $\mathrm{~A}_{3}$ & $\mathrm{D}_{2}$ & $\mathrm{D}_{10}$ & $\mathrm{D}_{12}$ & $\mathrm{D}_{1}$ & $\mathrm{C}_{2}$ & $\mathrm{~A}_{0}$ & $\mathrm{~A}_{4}$ & $\mathrm{C}_{4}$ & $\mathrm{~A}_{3}$ & $\mathrm{D}_{2}$ & $\mathrm{BN}_{15}$ \\
\hline 0 & 11 & 3 & 2 & 10 & 12 & 1 & 2 & 0 & 4 & 4 & 3 & 2 & 15 \\
\hline 0 & $\mathrm{~B}$ & 3 & 2 & $\mathrm{~A}$ & $\mathrm{C}$ & 1 & 2 & 0 & 4 & 4 & 3 & 2 & $\mathrm{~F}$ \\
\hline
\end{tabular}

Table 5: Fitness chromosome

\begin{tabular}{lc}
\hline Types & Frequency appear \\
\hline $\mathrm{a} \sin (\mathrm{bx})$ & 8 \\
$\mathrm{a} \cos (\mathrm{bx})$ & 8 \\
$\mathrm{a} \exp (\mathrm{bx})$ & 8 \\
$\mathrm{ax}^{\mathrm{n}}$ & 8 \\
$\mathrm{ax}$ & 1 \\
$\mathrm{a} \ln (\mathrm{x})$ & 1 \\
$\mathrm{a} \log (\mathrm{x})$ & 1 \\
$\mathrm{ax}$ & 1 \\
$\mathrm{a}$ & 1 \\
\hline
\end{tabular}

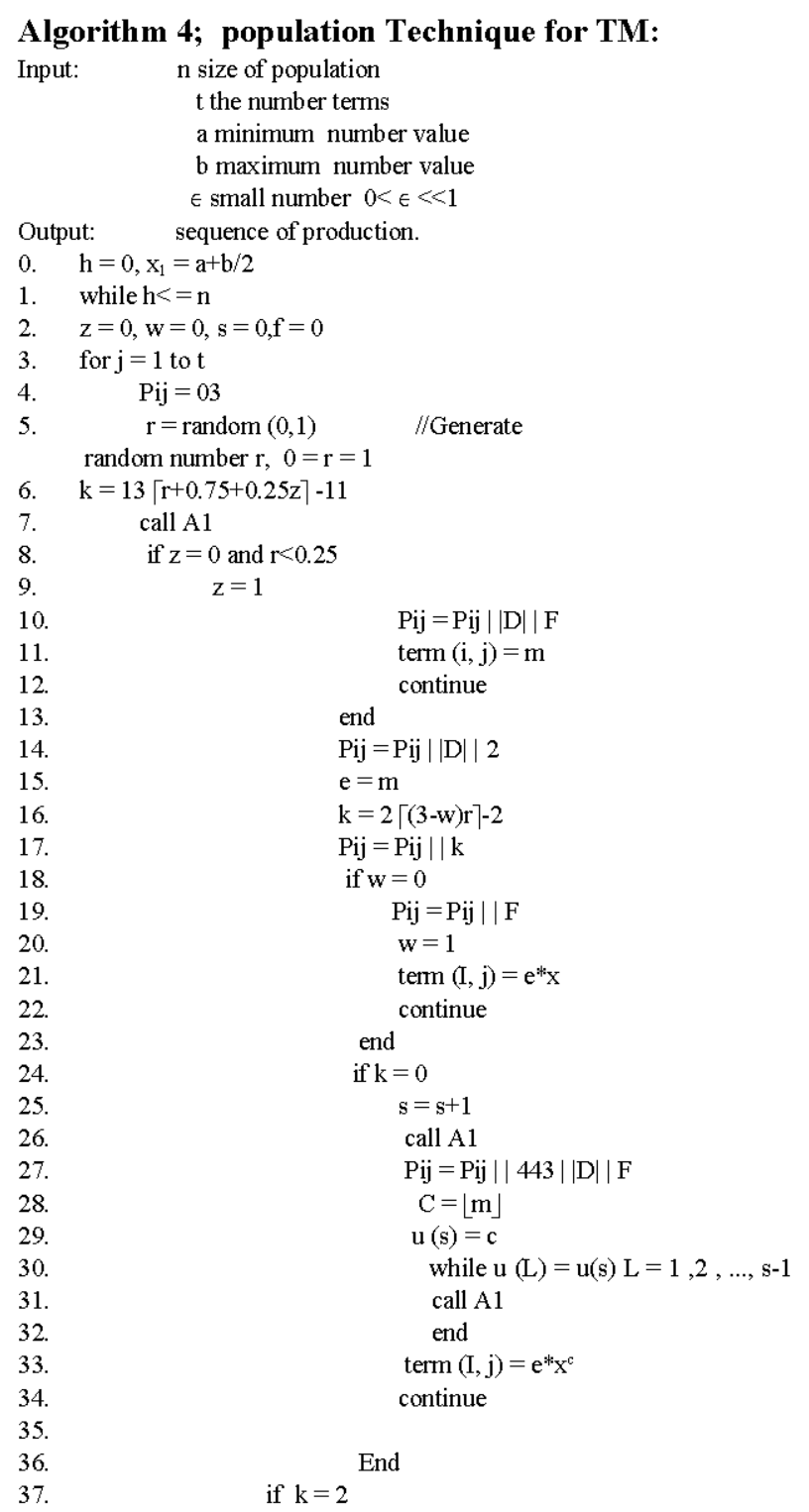

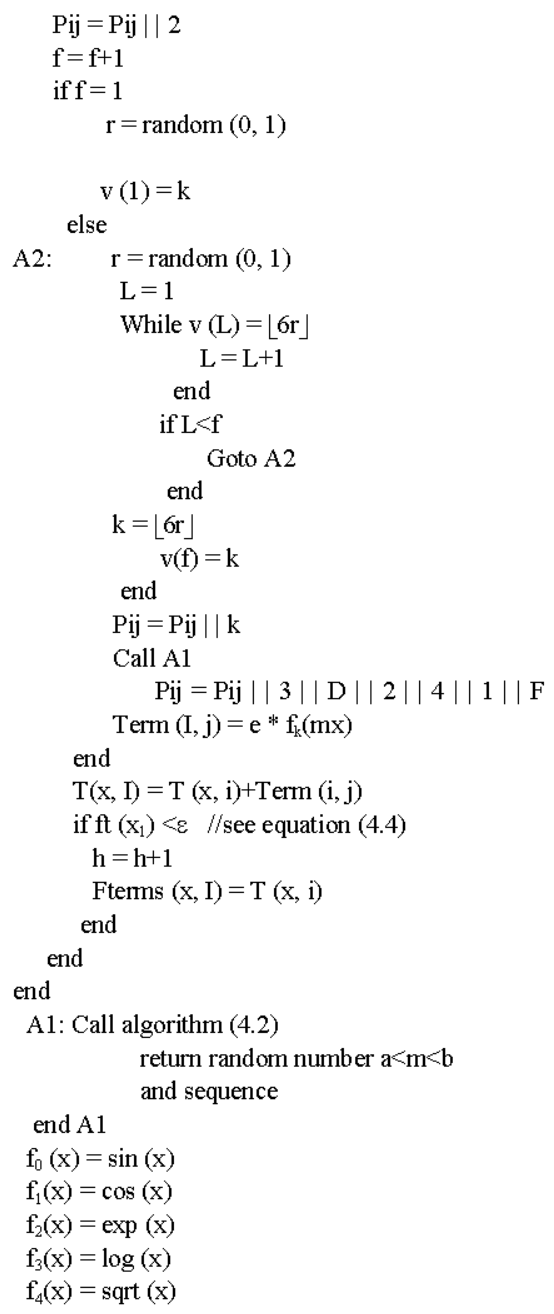

Algorithm 4 for using turing machines and development of grammatical evaluation to selection $n$ functions Fterms $(x, i)$ where $i=1,2, \ldots, n$. Suppose, the number terms in the function $f(x)$ is $t$, the number of types terms functions $T_{f}$ and the number frequency appears of each type term in the function $f(x)$ by the following Table 4 . where, $n_{i}=1,2, \ldots, \infty, I=1,2, \ldots, T_{f}$, then, if $n_{i}=\infty$, that mean $n_{i}$ is unbounded selection if the number of unbounded selection terms is $\mathrm{u}$ where $\mathrm{u}<\mathrm{T}_{\mathrm{f}}$, let $N_{t f}$ denoted to the number of class functions $f(x)$ for $t$ terms. Suppose $\mathrm{u}=4, \mathrm{~T}_{\mathrm{f}}=9$, then $\mathrm{p}=9-4=5$ and the number of frequency appears for each type term by the following (Table 6-7). 


\begin{tabular}{|c|c|c|c|c|c|c|c|c|c|}
\hline No. of function & Term type & $\mathrm{a}$ & $\mathrm{b}$ & Term type & $\mathrm{a}$ & $\mathrm{b}$ & Term type & $\mathrm{a}$ & $\mathrm{b}$ \\
\hline 1 & 6 & 1.652401 & 0 & 3 & 31.81481 & 7.574575 & 1 & 394490.1 & -0.82962 \\
\hline 2 & 4 & -584.837 & -6.72358 & 3 & -859.05 & 3.513305 & 4 & 84040.6 & -4.79501 \\
\hline 3 & 5 & 1.475907 & 0 & 2 & -441.614 & 2.776458 & 6 & 2.460912 & 0 \\
\hline 4 & 3 & -582.41 & 1.965864 & 4 & -164.374 & 9.890553 & 6 & -65.4199 & 0 \\
\hline 5 & 1 & 865.6072 & -6.64921 & 5 & -2.19092 & 0 & 3 & 3.507939 & 3.818017 \\
\hline 6 & 2 & -887.2 & 3.94388 & 5 & -1.4764 & 0 & 6 & 4.429936 & 0 \\
\hline 7 & 4 & 448.6314 & 8.66316 & 3 & -91.8146 & 0.139788 & 1 & 3380.286 & -7.67544 \\
\hline 8 & 2 & 1040.349 & -4.66 & 1 & 290.1992 & -0.45115 & 4 & -239.74 & -8.30968 \\
\hline 9 & 3 & -110.409 & -0.52447 & 5 & 0.57883 & 0 & 6 & -1.2585 & 0 \\
\hline 10 & 5 & 8.408849 & 0 & 1 & -762.876 & -8.99161 & 4 & 1879.738 & -6.05705 \\
\hline 11 & 3 & 349.937 & 7.020979 & 3 & 240.0716 & 6.270517 & 2 & 4508447 & 9.159198 \\
\hline 12 & 5 & 7.062136 & 0 & 4 & 635.3941 & 3.987232 & 6 & 0.748992 & 0 \\
\hline 13 & 5 & 2.946883 & 0 & 6 & 5.633692 & 0 & 1 & 4121.553 & 8.231961 \\
\hline 14 & 5 & -4.53996 & 0 & 4 & -354.754 & 7.692445 & 4 & 112.8967 & 9.465998 \\
\hline 15 & 5 & 2.331542 & 0 & 3 & 44.20943 & 3.442064 & 2 & 19793.89 & -4.1783 \\
\hline 16 & 5 & -1.87106 & 0 & 4 & -694.063 & -5.62833 & 2 & -1039.18 & 7.535217 \\
\hline 17 & 1 & -838.03 & -9.14302 & 5 & -8.87781 & 0 & 3 & -3.14296 & 4.696789 \\
\hline 18 & 4 & -172.981 & -9.39282 & 6 & 3.177752 & 0 & 5 & -5.63629 & 0 \\
\hline 19 & 5 & 0.956839 & 0 & 3 & -82.2317 & 6.680984 & 3 & $4.91 \mathrm{E}+08$ & -7.82789 \\
\hline 20 & 1 & -621.425 & -4.389 & 6 & 3.895267 & 0 & 5 & -8.24643 & 0 \\
\hline
\end{tabular}

\begin{tabular}{ll} 
Table 7: Frequency & \\
\hline Types & Function \\
\hline 1 & $\mathrm{a} \sin (\mathrm{bx})$ \\
2 & $\mathrm{a} \cos (\mathrm{bx})$ \\
3 & $\mathrm{a} \exp$ \\
4 & $\mathrm{a} \mathrm{x}$ \\
5 & $\mathrm{ax}$ \\
6 & $\mathrm{a}$ \\
\hline
\end{tabular}

Table 8: The types of terms are Types

\begin{tabular}{ll}
2 & $\mathrm{a} \cos (\mathrm{bx})$ \\
3 & $\mathrm{a} \mathrm{e} \mathrm{e}^{\mathrm{bx}}$ \\
4 & $\mathrm{a} \mathrm{x}$ \\
5 & $\mathrm{ax}$ \\
6 & $\mathrm{a}$ \\
\hline
\end{tabular}

Suppose:

$$
\begin{gathered}
\mathrm{n}_{\mathrm{t}}=\alpha\left\lfloor\frac{\alpha}{\mathrm{t}}\right\rfloor+\mathrm{p}\left\lceil\frac{\beta}{\beta+1}\right\rceil \\
\alpha=\operatorname{tmod}(\mathrm{p}+1), \beta=\left\lfloor\frac{\mathrm{t}}{\mathrm{p}+1}\right\rfloor
\end{gathered}
$$

Then:

$$
N_{t f}=\sum_{i=0}^{\eta_{t}}\left(\begin{array}{l}
p \\
i
\end{array}\right) u^{t-i}
$$

For $\mathrm{p}=5, \mathrm{t}=3$, then $\mathrm{N}_{\mathrm{tf}}=\sum_{\mathrm{i}=0}^{\mathrm{nt}}\left(\begin{array}{l}5 \\ \mathrm{i}\end{array}\right)^{3 . i \mathrm{i}}$ classes but there exist infinite function of three terms. From (4.7) if $t=p$, then $\mathrm{N}_{\mathrm{tf}}=(1+\mathrm{u})^{\mathrm{p}}$

Example 0: By using the above algorithm () where $\mathrm{n}$ $=20, \mathrm{t}=3, \mathrm{~T}_{\mathrm{f}}=9, \mathrm{u}=4, \mathrm{p}=5$ and differential equation is:

$$
\mathrm{Y}^{\prime \prime}-100 \mathrm{y}=0, \mathrm{y}(0)=0 \text { and } \mathrm{y}^{\prime}(0)=10
$$

\section{CONCLUSION}

In this study we offer a new method similar to the work of the method of grammatical evolution but do not depend on it where the use of mod and speed of the solution and less steps and a small storage grammatical evolution deepened on the conversion of chromosomes into functions according to certain rules. These functions are considered candidate solutions.

\section{REFERENCES}

Back, T. and F. Hoffmeister, 1991. Extended selection mechanisms in Genetic algorithms. Proceedings of the 4th International Conference on Genetic Algorithms and their Applications, (GAA'91), Morgan Kaufmann Publishers Inc., San Diego, CA., USA., pp: 92-99.

DeJong, K.A., 2006. Evolutionary Computation: A Unified Approach. MIT Press, Cambridge, Massachusetts, USA., ISBN:9780262041942, Pages: 268.

Goldberg, D.E., 1989. Genetic Algorithms in Search, Optimization and Machine Learning. 1st Edn., Addison-Wesley Professional, Boston, MA., USA., ISBN-13: 9780201157673 , Pages: 412.

Holland, J.H., 1975. Adaptation in Natural and Artificial System. University of Michigan Press, Ann Arbor, USA.

Jebari, K. and M. Madiafi, 2013. Selection methods for Genetic algorithms. Intl. J. Emerging Sci., 3: 333-344.

Kumar, R. and Jyotishree, 2012. Effect of polygamy with selection in Genetic algorithms. Intl. J. Soft Comput. Eng., 2: 194-199.

Kumar, R., G. Gopal and R. Kumar, 2013. Hybridization in Genetic algorithms. Intl. J. Adv. Res. Comput. Sci. Software Eng., 3: 403-409. 
Michalewicz, Z., 2007. Genetic Algorithms + Data Structures $=$ Evolution Programs. 3rd Edn., Springer, Berlin, Germany, ISBN:978-3-642-08233-7, Pages: 383. Mitchell, M., 1998. An Introduction to Genetic Algorithms. MIT Press, Cambridge, Massachusetts, USA., Pages: 203.
Razali, N.M. and J. Geraghty, 2011. Genetic algorithm performance with different selection strategies in solving TSP. Proceedings of the 2011 International World Congress on Engineering Vol. 2, July 6-8, 2011, WCE, London, UK., ISBN:978-988-19251-4-5, pp: 1134-1139. 